\title{
SOBRE LA CONSTITUCIÓN DE GRUPOS PARLAMENTARIOS Y EL «PRESTAMO» DE DIPUTADOS Y SENADORES
}

\author{
DAVID DELGADO RAMOS \\ Profesor Ayudante Doctor de Derecho Constitucional \\ Universidad Rey Juan Carlos
}

SUMARIO

I. Introducción. II. La constitución de los grupos parlamentarios en las Cortes Generales. III. El préstamo de parlamentarios tras la constitución de las cámaras. IV. La sentencia 76/2017. V. Conclusiones.

\section{INTRODUCCIÓN}

Tras la repetición de las elecciones generales del 20 de junio de 2016, y la posterior constitución de las Cámaras en el mes de julio, se inició el proceso de conformación de los diversos grupos parlamentarios que, sin embargo, se encontró en la XII Legislatura con la negativa de la Mesa del Senado a respaldar la constitución del Grupo Parlamentario Catalán (CDC), compuesto por senadores del Partido Demócrata Català, al sostener que no se cumplían los requisitos que establecía el Reglamento para la constitución de dicho grupo, conllevando el pase de sus cuatro senadores al Grupo Mixto, pese a que lograron sumar los exigidos para poder constituirse en grupo.

Una situación inédita, toda vez que, aunque existían fundamentos jurídicos que respaldasen la decisión de la Mesa, dichos fundamentos habían sido deliberadamente soslayados en legislaturas anteriores, estableciendo un precedente que se había consolidado en una suerte de costumbre parlamentaria.

Una decisión de hondas implicaciones, dado que, junto a los beneficios políticos que conlleva la pertenencia a un grupo parlamentario, - formar parte de la Junta de Portavoces, participación en la conformación del orden del día, mayor capacidad en el ejercicio del control parlamentario-, existen otros, económicos y de medios, no menores, — dotación de personal y medios materiales, incremento de las subvenciones recibidas-, que potencian la acción política parlamentaria de los partidos con grupo propio. 
Por ello, dicha negativa fue respondida con la interposición de un recurso de amparo que, estimado por el Tribunal Constitucional, declaró la nulidad de los acuerdos de la Mesa por vulneración del artículo 23.2 de la Constitución.

En este trabajo pretendemos analizar la sentencia y, previamente, los criterios utilizados en la constitución de los grupos parlamentarios, incidiendo especialmente en una práctica políticamente tan común como jurídicamente discutible: el «préstamo» de diputados y senadores, sin olvidar la jurisprudencia constitucional sobre la constitución de los grupos y su praxis política histórica.

\section{LA CONSTITUCIÓN DE LOS GRUPOS PARLAMENTARIOS EN LAS CORTES GENERALES}

La constitución de los grupos parlamentarios se encuentra recogida, en el Congreso de los Diputados, en los artículos 23 y 24 de su Reglamento, articulándose en torno a la conjunción de una serie de requisitos materiales, —número mínimo de quince diputados, salvo que con carácter subsidiario se aplique el de número mínimo de cinco, siempre y cuando hubiesen obtenido el quince por ciento de los votos en las circunscripciones en las que se presentaron o el cinco por ciento nacional; la prohibición de constitución de grupos separados de diputados de un mismo partido o que pertenezcan a formaciones que no se hayan enfrentado electoralmente-, y formales, — constitución en los cinco días posteriores a la sesión constitutiva del Congreso mediante escrito a la Mesa; su denominación, portavoz e integrantes; $y$, por último, los diputados asociados a grupos.

Sin embargo, la aparente claridad del tenor de los artículos 23 y 24 del Reglamento no ha sido obstáculo para que, desde la primera legislatura, se tratasen de sortear dichos requisitos, bien sea por vía del cociente nacional del cinco por ciento, o bien por medio de la representatividad territorial en determinadas circunscripciones.

Hay que tener en cuenta que el apartado primero del artículo 23, relativo a las vías de constitución de los grupos parlamentarios, ha generado notable confusión, propiciando interpretaciones sesgadas al objeto de facilitar la constitución de los grupos. Una confusión explicable, dado que el cálculo del quince por ciento de los sufragios en las distintas circunscripciones podía interpretarse, bien en cada una de las circunscripciones, o bien en el conjunto de ellas. Finalmente, la Cámara, a mediados de los años noventa, aclaró la cuestión apostando por la segunda interpretación ${ }^{1}$, aunque no por ello la problemática confusión haya sido resuelta, como veremos más adelante.

1 Explicó la Secretaría General de la Cámara que «el 15 por 100 de los votos no ha de obtenerse en cada una de las circunscripciones en que presenta una candidatura una entidad politica, sino en el conjunto de las circunscripciones, conclusión a la que se llega no solamente desde la interpretación literal del precepto sino también desde la analógica a tener de lo establecido en el supuesto anterior —el 5 por 100 del conjunto nacional, y no en cada una de las circunscripciones de 
El apartado segundo del artículo 23 también ha sido objeto de sesgada interpretación, toda vez que se ha querido entender, —y se ha entendido-, bajo la expresión «en ningún caso pueden constituir Grupo Parlamentario separado Diputados que pertenezcan a un mismo partido», en conexión con la figura del diputado «asociado» establecida por el artículo 24, que un diputado que forma parte de un grupo parlamentario puede asociarse a otro a efectos de su constitución, pero sin formar parte de él, obviando con ello la interpretación establecida por la Cámara, que entiende en este precepto que «todos los diputados que concurren bajo las mismas siglas han de reunirse en el mismo grupo» ${ }^{2}$.

El resultado de esta falta de claridad normativa ha sido la formación, en demasiadas ocasiones, de grupos que, sorteando la letra y el sentido de las limitaciones reglamentarias, han desvirtuado la normativa parlamentaria y quebrado la estrecha relación entre la representación parlamentaria y la representación electoral ${ }^{3}$. Una circunstancia cuya gravedad se amplía si se tiene en cuenta que esta disfuncional anomalía abre la puerta a la constitución de grupos con miembros provenientes de otras candidaturas: es el mal llamado «préstamo» de parlamentarios.

En el caso del Senado, la cuestión plantea problemas similares, si bien el umbral mínimo para la conformación de un grupo parlamentario es superior y único, —al no existir el requisito subsidiario del Congreso—, situándose en diez el número de senadores requerido a tenor de lo dispuesto en el artículo 27.1 del Reglamento del Senado.

Sin embargo, la nota relevante radica en que, estableciendo los mismos criterios en cuanto a los plazos, — las prohibiciones de pertenecer a más de un grupo y no constituir grupos distintos si han formado parte de la misma candidatura electoral-, introduce dos variables no menores: el establecimiento de una cifra mínima de seis senadores para ser grupo (art. 27.2 del Reglamento del Senado), - no la mitad del constituido al inicio de la legislatura, como en el Congreso-, y la denominación del mismo «conforme con la que sus miembros concurrieron a las elecciones» (art. 27.4 del Reglamento).

\section{EL PRÉSTAMO DE PARLAMENTARIOS TRAS LA CONSTITUCIÓN DE LAS CÁMARAS}

Este «préstamo» de diputados o senadores se ha constituido en una suerte de costumbre parlamentaria, una práctica habitual de nuestro parlamentarismo cuyo

\footnotetext{
la nación—». «Nota de la Secretaría General del Congreso de los Diputados sobre requisitos materiales para la constitución de grupo parlamentario en el Congreso de los Diputados», RCG, n. ${ }^{\circ}$ 34, 1995, p. 217.

2 «Nota de la Secretaría General del Congreso de los Diputados sobre requisitos materiales para la constitución de grupo parlamentario en el Congreso de los Diputados». Op. cit., p. 222.

3 Presno Linera, M. A. «El fin del «préstamo» de parlamentarios?». Repertorio Aranzadi del Tribunal Constitucional, n. ${ }^{\circ}$ 5, 2002, p. 2048.
} 
origen se remonta, en nuestra historia democrática, a la III Legislatura (19861989) en el Senado y a la V legislatura (1993-1996) en el Congreso de los Diputados, habiendo sido utilizada desde entonces en función de las conveniencias políticas de los grupos mayoritarios, y casi siempre con un único beneficiario: los grupos nacionalistas.

En ambas Cámaras, la potestad de verificación, de constatación, del cumplimiento de los requisitos para poder constituirse en grupo es única y exclusivamente de la Mesa como intérprete exclusivo del reglamento parlamentario, lo que introduce una variable de peligrosa discrecionalidad que se compadece poco con la vertiente institucional, de absoluta imparcialidad, que debe presidir su funcionamiento no sólo como órgano rector de la Cámara, sino como garante de las minorías.

En ese sentido, con ocasión de la constitución de la V Legislatura en el Congreso de los Diputados se planteó por vez primera esta cuestión, cuando Coalición Canaria, que sí había superado en las dos circunscripciones en las que se había presentado el quince por ciento de los sufragios, no había logrado los cinco escaños exigidos por el Reglamento, — había obtenido cuatro—, por lo que no podía formar grupo parlamentario propio.

Para constituirse en grupo, sumó a sus cuatro diputados uno más elegido por el Partido Aragonés Regionalista quien, pocos días después de haberse constituido el Grupo Parlamentario de Coalición Canaria, lo abandonó para integrarse en el Grupo Mixto, previsión permitida por el artículo 27.1 del Reglamento, que determina que el pase de un grupo a otro sólo se podrá realizar dentro de los cinco primeros días de cada periodo de sesiones, salvo el pase al Grupo Mixto, que se podrá efectuar en cualquier momento.

En este contexto, se planteó la posibilidad de que el Grupo Canario hubiese incurrido en causa de disolución, bien por ineficacia sobrevenida de la declaración de voluntad originaria de constitución del grupo, o bien por fraude de ley para eludir la norma. Cuestiones que, analizadas, llevaron a la conclusión de que no procedía la disolución ${ }^{4}$.

Posteriormente, se volvió a plantear en la VI Legislatura (1996-2000), también con Coalición Canaria, aunque esta vez el protagonista fue Unión del Pueblo Navarro (UPN), que aportó no uno, sino dos diputados a los cuatro que había obtenido Coalición Canaria. De nuevo, la Mesa declaró constituido el Grupo Canario para, posteriormente, abandonar los dos diputados de UPN dicho Grupo para integrarse en el Grupo Popular.

No obstante, se produjo una paradójica interpretación reglamentaria, dado que, en puridad, los dos diputados de UPN no debieron ser autorizados a

4 Para dilucidar la cuestión se solicitó un informe a la Secretaría General del Congreso de los Diputados que, si bien consideró que no procedía la disolución, estimó que había argumentos a favor y en contra de la existencia de fraude de ley. «Nota de la Secretaría General del Congreso de los Diputados acerca de la incidencia sobre un grupo parlamentario del cambio de grupo por parte de un señor diputado». $R C G, \mathrm{n} .^{\circ} 31$, 1994, p. 197. 
integrarse en el Grupo Canario, dado que UPN sólo podía integrarse en el Grupo Popular por ser una formación «asociada» al Partido Popular en Navarra, donde éste no concurría y, por lo tanto, a tenor del artículo 23.2 del Reglamento del Congreso, no podía formar parte de otro grupo que no fuese el Popular porque no se habían enfrentado en las elecciones.

Pese a la evidencia en contra, la Mesa autorizó la constitución del Grupo al entender que el artículo 23.2 del Reglamento, que prohíbe la constitución de grupos parlamentarios separados cuando las formaciones políticas no se hayan enfrentado electoralmente, no impide, sin embargo, "que alguna de ellas ceda sus Diputados a otra formación para el cumplimiento de los mínimos previstos en el párrafo primero de dicho precepto». Un planteamiento que veladamente trataba de esconder lo que era un auténtico fraude de $l e y^{5}$, consagrando así el «préstamo» como costumbre parlamentaria.

En la VII Legislatura (2000-2004) se produjo una situación peculiar, objeto de recurso de amparo ante del TC, en la medida en que se volvió a declarar constituido el Grupo Parlamentario de Coalición Canaria, —formado por cuatro diputados de Coalición Canaria y tres de UPN_-, mientras se denegaba la constitución del Grupo Parlamentario Galego, — constituido por tres diputados del BNG, uno del PNV y otro de CIU-.

En el caso de Coalición Canaria, se interpretó que, pese a que UPN no había competido contra Coalición Canaria, se producía una simple cesión de diputados, dado que el porcentaje de sus votos no se había utilizado para la constitución del Grupo Popular. Por el contrario, en el caso del BNG, a sus tres diputados sumaba dos, pero provenientes de dos candidaturas distintas que, además, no se habían enfrentado electoralmente, por lo que se infringía, doblemente, la prohibición del artículo 23.2 del Reglamento. Además, existía una infracción adicional: los porcentajes de votos de los diputados de CIU y PNV habían sido ya utilizados para constituir los Grupos Catalán y Vasco.

Por último, y como ejemplo de la discrecionalidad interpretativa atribuida a la Mesa, conviene analizar los casos de la constitución de los grupos parlamentarios de Esquerra Republicana, Amaiur, y Unión, Progreso y Democracia en legislaturas diferentes.

Respecto del primer caso, tuvo lugar tras la constitución de la VIII Legislatura (2004-2008), cuando la candidatura de ERC disparó sus resultados electorales, pasando de un escaño y el 5,64 por ciento de los votos en las Elecciones Generales de marzo de 2000 a ocho diputados y el 15,89 por ciento de los votos en las Elecciones de marzo de 2004.

Pese a no superar en todas las circunscripciones en las que concurría el quince por ciento, solicitó constituirse en grupo, lo que fue autorizado por la Mesa, que

5 Giménez Gluck, D., «Constitución y extinción de un grupo parlamentario en el Congreso de los Diputados (especial referencia al caso de Coalición Canaria en la VIII legislatura)». CDP, n. ${ }^{\circ}$ 29, 2006, p. 117. 
consideró que dicho quince por ciento se debía entender en el conjunto de las circunscripciones, esto es, la media de todas ellas. Una interpretación que no se produjo ex novo, ya que ya se había aplicado en la III Legislatura (1986-1989), cuando se permitió la constitución del Grupo Vasco aun no alcanzando el quince por ciento en Navarra ${ }^{6}$.

Por otro lado, en esa misma legislatura, Coalición Canaria tenía tres diputados pero, en este caso, quien contribuyó a la formación del Grupo de Coalición Canaria-Nueva Canarias fue el Grupo Socialista, vencedor de las Elecciones Generales que necesitaba de los votos de Coalición Canaria para lograr la investidura de su candidato a Presidente del Gobierno. De nuevo, los dos diputados socialistas pasaron en el siguiente periodo de sesiones al Grupo Socialista, por lo que el Grupo Canario se quedó en tres.

En segundo lugar, el caso de Amaiur en la X Legislatura (2011-2016) resulta aún más significativo de la discrecionalidad de la Mesa, dado que sus resultados guardaban un extraordinario parecido con los obtenidos recurrentemente por la candidatura del PNV, ya que, en ambos casos, las candidaturas habían superado el quince por ciento de los votos en todas las circunscripciones en las que se habían presentado, salvo en Navarra.

Sin embargo, pese a que la Mesa permitió la constitución del Grupo Vasco, fue mucho más restrictiva con Amaiur, al entender que, pese a haber obtenido escaño en la circunscripción de Navarra, el no alcanzar el quince por ciento exigido por el Reglamento le imposibilitaba para constituirse en grupo, por lo que tuvo que pasarse al Grupo Mixto. Amaiur recurrió en amparo, siendo inadmitido.

En este caso, la Mesa del Congreso utilizó la argumentación esgrimida por el TC en su sentencia 64/2002, según la cual, para la constitución efectiva del grupo parlamentario se exige que el quince por ciento de los votos se computen en las circunscripciones donde se ha presentado candidatura y, además, obtenido escaño, lo que no ocurría en el caso del PNV en Navarra, pero sí en el caso de Amaiur.

En la IX Legislatura (2008-2011), por otro lado, IU necesitó del «préstamo» de diputados, — dado que tenía dos diputados—-, debiendo unirse a ERC y BNG no sólo para alcanzar —y superar - los cinco diputados, sino para poder superar también el cinco por ciento nacional de los votos, lo que les permitió constituirse en grupo que, ya constituido, fue abandonado por los dos diputados del BNG para pasar al Mixto.

6 Técnicamente, hay una diferencia entre los casos de ERC y PNV, dado que, en el primer caso, la media utilizada es fruto de la media de los porcentajes donde la candidatura ha obtenido escaño, mientras que, en el segundo caso, en la III Legislatura, se utilizó la media de las cuatro circunscripciones (las tres del País Vasco y la de Navarra). Además, en el caso de ERC, que no alcanzó el quince por ciento en Barcelona, se utilizó la media de votos a nivel autonómico, no la suma de los porcentajes de las cuatro circunscripciones por separado, cuya media hubiese sido inferior al quince por ciento. En el caso del PNV, no se utilizó la media autonómica (porcentaje total en País Vasco y Navarra), porque resultaba de media inferior al quince por ciento del total. 
Por último, en el caso del Grupo Parlamentario de UPyD en la X Legislatura, había obtenido cinco diputados y el 4,7\% de los votos, por lo que sólo cumplía parcialmente los requisitos del artículo 23.1 del Reglamento, lo que requirió, al objeto de alcanzar el cinco por ciento nacional, que Foro Asturias le cediese su único diputado. Diputado que abandonaría una vez constituido el Grupo para integrarse en el Grupo Mixto.

Por otro lado, en el Senado, el «préstamo» de senadores comenzó antes que en el Congreso, ya que se ha producido desde la II Legislatura (1982-1986), teniendo como beneficiario principal al Grupo Vasco, que ha podido ser sistemáticamente constituido gracias al constante «préstamo» por parte de diversos grupos (II, III, IV, V, VI, VIII, IX, X y XII Legislaturas), en una práctica también compartida por Coalición Canaria (V y VII Legislaturas) y CIU (VIII, IX y XI Legislaturas).

En la II Legislatura (1982-1986), el Grupo Parlamentario Socialista cedió un senador al grupo de senadores del PNV, que pudo así constituirse en el Grupo Vasco.

En la III Legislatura (1986-1989), los grupos parlamentarios del CDS y del PNV se beneficiaron del préstamo de senadores, — tres en el caso del CDS, elegidos en la candidatura de Coalición Popular; uno en el caso del PNV, de las Agrupaciones Independientes de Canarias-.

En la IV Legislatura (1989-1993), de nuevo el PNV y el CDS protagonizaron el «préstamo» de senadores entre grupos, ya que el Grupo Socialista volvió a ceder senadores al PNV, - tres- ya que necesitó también de otros dos senadores del Grupo Catalán de CIU. El CDS, por su parte, necesitó cuatro senadores.

En la V Legislatura (1993-1996), Coalición Canaria se constituyó en grupo parlamentario gracias a la cesión de dos senadores de CIU y otros dos integrados en el Grupo Mixto, —uno del Partido Riojano y otro de IU—, mientras que el PNV, de nuevo, cambió de «prestador», dado que fue CIU quien le cedió los cuatro que necesitaba ${ }^{7}$.

En la VI Legislatura (1996-2000), fue el Grupo Socialista quien cedió al PNV los cuatro senadores que le faltaban.

En la VII Legislatura (2000-2004), el PNV no necesitó de cesión alguna, pudiendo constituirse en grupo sin apoyo de otros grupos, pero sí lo necesitó Coalición Canaria, que requirió cuatro senadores al Grupo Popular.

En la VIII Legislatura (2004-2008), el Grupo Socialista volvió a ceder senadores, esta vez no sólo al PNV, sino también a Convergència, con tres y cuatro, respectivamente.

7 El PNV sólo alcanzó los tres senadores, un ejemplo más de una práctica después mucho más frecuente: el prestador cede más senadores de los que tiene el prestatario. 
En la IX Legislatura (2008-2011), el Grupo Parlamentario Socialista prestó otra vez senadores a Convergència, tres esta vez, mientras que el PNV, que tenía tan sólo dos senadores, le prestó siete, que se sumarían a uno de Coalición Canaria y, posteriormente, uno del BNG, conformando el Grupo de Senadores Nacionalistas.

En la X Legislatura (2011-2016), de nuevo el PSOE cedió cinco senadores al PNV.

Tras las Elecciones Generales de 20 de diciembre de 2015, que dieron paso a la brevísima XI Legislatura, el «préstamo» de senadores se produjo en tres grupos parlamentarios, ya que el PNV constituyó su grupo gracias a la cesión de dos senadores de Coalición Canaria y la senadora de Cambio-Aldaketa, y ERC y Democràcia i Llibertat gracias a dos senadores del PSOE.

Sin embargo, esta pacífica práctica, que no había sido objeto de especiales conflictos en el Senado, más allá de la permanente constatación de un evidente fraude de ley reglamentario, quebró en los inicios de la XII Legislatura, — la vigente-, cuando, pese a que, una vez más, el PNV pudo constituirse en grupo gracias a la cesión de cuatro senadores del Partido Popular, se denegó la constitución de un grupo.

En este caso, la Mesa del Senado, - mediante Acuerdo que dará lugar al recurso de amparo que resolverá el TC en la sentencia 76/2017, de 29 de junio-, impidió la constitución del Grupo Parlamentario de Democràcia i Llibertat, que tenía cuatro senadores, al estimar que no se cumplían de ningún modo los requisitos establecidos por el Reglamento, — pese a que había intentado sumar a sus parlamentarios dos elegidos en la candidatura de ERC, otros dos de Coalición Canaria y uno más de Agrupación Socialista Gomera y de EH Bildu—, por lo que tuvieron que pasar al Grupo Mixto.

\section{LA SENTENCIA 76/2017}

\section{Precedentes jurisprudenciales}

La STC 76/2017 ha tenido, al menos, dos precedentes jurisprudenciales ante el Tribunal Constitucional sobre la constitución de los grupos parlamentarios: las SSTC 64/2002, de 11 de marzo, y la 141/2007, de 18 de junio.

La primera de ellas, la STC 64/2002, de 11 de marzo, resolvía el recurso de amparo interpuesto contra el Acuerdo de la Mesa del Congreso que denegó la constitución del Grupo Parlamentario Galego (BNG) en la VII Legislatura (2000-2004).

En aquel momento, tras las Elecciones Generales del 12 de marzo del año 2000, el BNG había obtenido tres escaños, por lo que no alcanzaba el umbral mínimo establecido para poder constituirse en grupo, por lo que, con la anuencia y el «préstamo» de un diputado del PNV y otro de CIU, solicitó constituirse como Grupo Parlamentario Galego (BNG). 
La Mesa del Congreso, sin embargo, estimó que con base en el artículo 23.1 del Reglamento no se cumplían los requisitos, dado que, si bien sumaban cinco diputados, en conjunto no superaban el quince por ciento de los votos en las circunscripciones en las que se habían presentado, ya que los porcentajes del diputado del PNV y del de CIU habían sido ya utilizados para la conformación de los grupos parlamentarios Catalán y Vasco, por lo que no podían usarse dos veces para constituir grupos distintos.

Para los recurrentes, los Acuerdos de la Mesa suponían una vulneración de los artículos 23.1 y $2 \mathrm{CE}$, por dos motivos: la ausencia de motivación de la decisión, creando además una nueva línea interpretativa en el ámbito de la creación de los grupos parlamentarios única y exclusivamente para este caso concreto, obviando los precedentes; y, por otro lado, se había conculcado el principio de igualdad, ya que la negativa a la solicitud de creación del Grupo Galego no se ha producido en casos similares, como en el caso del Grupo de Coalición Canaria en la V, VI y VII Legislaturas (1993-1996, 1996-2000 y 2000-2004) o, remotamente, la del Grupo Andalucista en la I Legislatura (1979-1982).

Para el Tribunal, "no cabe duda de alguna de que la facultad de constituir Grupo Parlamentario, en la forma y con los requisitos que el mismo Reglamento establece, corresponde a los Diputados», por lo que las facultades conferidas a la Mesa n este ámbito "son de carácter reglado, debiendo circunscribirse a constatar si la constitución del Grupo Parlamentario reúne los requisitos reglamentariamente establecidos, debiendo rechazar, en caso de incumplimiento de aquellos requisitos, salvo que resulten subsanables, la pretensión de constituir Grupo Parlamentario» (FJ 3). Con ello, establece una limitación clara a la discrecionalidad de la Mesa, que sólo debe recoger la declaración de voluntad de los diputados que pretenden constituirse en grupo y constatar el cumplimiento de los requisitos, pero no entrar en valoraciones.

En relación con los artículos 23.1 y 2 de la Constitución, y tras constatar el cómputo de porcentaje de votos por candidaturas en las circunscripciones a efectos de analizar si se ha alcanzado el quince por ciento exigido por el artículo 23.1 del Reglamento, el Tribunal entiende que, «en una interpretación del mencionado precepto reglamentario coherente con la configuración constitucional de nuestro sistema electoral, únicamente puede ser entendida como referida a las candidaturas presentadas por las formaciones politicas en aquellas circunscripciones en que bubieran concurrido a las elecciones y en las que figuran y han sido elegidos los Diputados que pretenden constituir Grupo Parlamentario» (FJ 5). Con ello, rechaza el carácter arbitrario o desproporcionado que para los demandantes ha tenido la interpretación reglamentaria de la Mesa.

Además, introduce con este argumento una aclaración interpretativa en la confusa redacción del artículo 23.1 del Reglamento que, poco después, servirá a la Mesa para validar la constitución del Grupo Parlamentario de ERC en 2004 y no hacerlo con ocasión, en 2011, del intento de constituir grupo de la coalición Amaiur: para computar el quince por ciento de los votos en una circunscripción a efectos de constituir grupo parlamentario, en ésta se debía haber obtenido, además del quince por ciento de los votos, diputado. 
En ese sentido, el Tribunal entiende que el requisito subsidiario de cinco escaños y, al menos, el quince por ciento de los votos en las circunscripciones en las que se hubieren presentado para la constitución de grupo, tiene una naturaleza excepcional, al reducir «el requisito numérico, pero a la vez adicionando al mismo la exigencia de un cierto respaldo electoral» (FJ 6), por lo que no resulta admisible «que el porcentaje de votos o el respaldo electoral obtenido por las candidaturas presentadas por una formación política sea utilizado o invocado para constituir un Grupo Parlamentario diferente al de éstos, en definitiva, que aquel porcentaje de votos sea utilizado o invocado para constituir dos Grupos Parlamentarios distintos por los Diputados elegidos en las candidaturas de una misma formación politica» (FJ 6). En suma, que una vez computado el porcentaje de votos de una candidatura a efectos del 23.1 del Reglamento, dicho porcentaje no puede ser de nuevo valorado para constituir otro grupo.

Por último, y en relación con la segunda de las vertientes del artículo 23.2 $\mathrm{CE}$, relativa al principio de igualdad utilizando como base argumental los precedentes del Grupo Andalucista o el Grupo de Coalición Canaria, ambos ejemplos son rechazados, ya que el primero se produjo tras una reforma del Reglamento del Congreso, por lo que «fue constituido por el número de Diputados reglamentariamente exigido»; y, en el caso del segundo, porque en los dos supuestos planteados, en el primero, no se computaba el porcentaje de votos a efectos de su constitución como grupo parlamentario, «sino la posible disolución del Grupo Parlamentario de Coalición Canaria por haberlo abandonado uno de sus componentes». En definitiva, desestima el amparo y valida la interpretación de la Mesa en la denegación de la constitución del grupo parlamentario.

Por otro lado, la segunda de las sentencias sobre la constitución de grupos parlamentarios, la STC 141/2007, de 18 de junio, denegaba el amparo a un recurso interpuesto por dos diputados del Parlamento de La Rioja cuyo grupo parlamentario, —formado sólo por ellos dos—, había sido disuelto tras una modificación del reglamento de la cámara, provocando su pase al grupo mixto, constituido tan sólo por ellos.

Para los diputados recurrentes, elegidos en las elecciones de 1999 y constituidos en Grupo Parlamentario del Partido Riojano de acuerdo con el entonces vigente Reglamento del Parlamento, la modificación reglamentaria de 2001 les supuso la conculcación de los artículos 9, 23 y 24 CE, ya que se les había integrado en el grupo mixto, limitando su capacidad de intervención parlamentaria y sus recursos.

En ese sentido, sostenían que su pertenencia a un determinado grupo parlamentario era indisociable de su estatus representativo como diputados, careciendo la Mesa de potestad para declarar su disolución salvo en los casos reglamentariamente establecidos, ya que su intervención es meramente declarativa, de constatación del cumplimiento de los requisitos. Requisitos que, por otro lado, ya se habían cumplido, ya que el grupo parlamentario se había constituido según la normativa vigente en ese momento. 
Por último, a tenor de los recurrentes, la Mesa había incurrido en un error de derecho al establecer un régimen transitorio sobre constitución de grupos no previsto por el Reglamento, aplicando retroactivamente una norma a un grupo previamente constituido.

Para el TC, y en relación con los artículos 23.1 y 2 CE, la participación de los ciudadanos en las funciones y cargos públicos a través de representantes se define como un derecho «de configuración legal, en el sentido de que compete a los Reglamentos parlamentarios fijar y ordenar los derechos y atribuciones que a los parlamentarios corresponden», por lo que, para considerar su conculcación, no vale cualquier acto, sino sólo aquellos que tengan relevancia constitucional, esto es, los que "pertenezcan al núcleo de su función representativa parlamentaria, como son, indudablemente, el ejercicio de la función legislativa o de control de la acción del Gobierno» (FJ 3).

Así, el Tribunal rechaza la discriminación, ya que "no se deduce una intención expresa de adecuar las normas sobre constitución de grupos parlamentarios a la situación de los demandantes sino más bien de adaptar las previsiones del Reglamento del Parlamento de La Rioja a las de la mayoría de normas parlamentarias similares», sin olvidar que, tratándose de una norma de carácter general, "no puede considerarse que se aplicara exclusivamente a algunos parlamentarios por la única razón de que sólo ellos estuvieran incluidos en ese momento en el supuesto establecido por el Reglamento» (FJ 5).

Sin embargo, reconoce el Constitucional, en relación con la retroactividad aplicada por el Reglamento que, aunque disponga de capacidad de organización derivada de la autonomía parlamentaria, sí ha restringido los derechos de los parlamentarios «sin especifica cobertura legal o reglamentaria. En ausencia de disposiciones relativas a la aplicación transitoria del nuevo Reglamento de la Cámara, los acuerdos cuestionados optaron por la interpretación más lesiva de los derechos a constituir grupo parlamentario y participar en los debates parlamentarios, alterando las normas que hasta el momento regían su ejercicio», lo que ha supuesto la lesión del artículo 23.2 CE, al "privar ilegítimamente a los parlamentarios de los derechos básicos que integran la esencia de su función representativa» (FJ 5). En suma, otorga el amparo a los recurrentes, anulando todos y cada uno de los acuerdos de la Mesa impugnados.

\section{La sentencia $76 / 2017$}

Conviene resaltar una cuestión esencial, y es que los dos senadores elegidos en la candidatura del Partit Demòcrata Català incumplían doblemente en aquel momento lo dispuesto en el Reglamento del Senado para poder constituirse en grupo parlamentario, dado que no sólo no alcanzaban los diez senadores exigidos en el artículo 27.1, sino que, al manifestar su voluntad de constituirse en grupo, incumplían también lo dispuesto en el artículo 27.4, esto es, adoptar una denominación acorde a la utilizada por sus miembros al concurrir en las elecciones, ya que, pese a que sí lograron sumar otros ocho senadores, — «prestados», 
provenientes de las candidaturas de ERC (dos), Coalición Canaria (dos), Agrupación Socialista Gomera (uno) y Bildu (uno)—, el grupo pretendió constituirse bajo la denominación de «Grupo Parlamentario Catalán en el Senado (CDC)», que no era la candidatura común de todos los senadores.

Dicho esto, la negativa de la Mesa, — con un informe de los servicios jurídicos en contra-, se basó en una interpretación conjunta y sistemática de los artículos 27.1, 27.2 y 28.2 del Reglamento, al considerar, pro futuro, que dado que los senadores "prestados» se darían de baja del grupo una vez constituido para pasar al grupo mixto, y que el Grupo Catalán se quedaría con cuatro, el grupo incurriría en causa de disolución al estar formado por menos de seis miembros.

Este segundo punto fue contestado por los demandantes al afirmar que el grupo sí tenía vocación de permanencia y que sus miembros no descenderían de seis, ya que los dos senadores de Coalición Canaria no tenían intención alguna de darse de baja del Grupo Catalán, por lo que no habría causa de disolución.

Pese a ello, en su segundo Acuerdo reafirmó el planteamiento, estimando que se podría «calificar de antijurídica la posibilidad de constituir un Grupo Parlamentario, aunque se reúnan diez o más firmas, si, nada más transcurrido el plazo reglamentario de cinco días hábiles, el número de los mismos resulta ser inferior a seis».

Los recurrentes, en ese sentido, entienden vulnerados los derechos de los artículos 14 y $23 \mathrm{CE}$, puesto que no existen razones jurídico-objetivas determinantes para denegar la constitución del Grupo Catalán, al cumplirse todos los requisitos reglamentarios.

Por un lado, la constitución establecida en el artículo 27.1 se cumple, toda vez que, no disponiendo de los diez senadores necesarios para formalizarla, se habilita la vía del «préstamo», parlamentariamente admitida y consagrada en precedentes, alcanzando gracias a otras cuatro formaciones políticas el número mínimo establecido.

Y, por el otro, en relación con la disolución del grupo del artículo 27.2, para los recurrentes opera sólo cuando el grupo haya sido formalmente constituido, nunca antes, por lo que la consideración de la Mesa es innecesaria por improcedente al adelantar un presupuesto de hecho inexistente.

El principio de igualdad, por su parte, lo entienden conculcado en la medida en que se ha denegado la constitución del Grupo Catalán mientras que se ha posibilitado la del Grupo Vasco, que también ha requerido de cuatro senadores «prestados» provenientes del Grupo Popular. Ciertamente, utilizándose el mismo criterio ex post que la Mesa, se advierte de la falta de concordancia entre ambos casos, porque el supuesto de hecho planteado por la Mesa en su argumentación no resulta válido, ya que el PNV, aún con los cuatro senadores «prestados», no descendería, en ningún caso, de los seis con los que cuenta y, por lo tanto, no incurriría en la causa de disolución del artículo 27.2.

Para el Tribunal, la constitución del Grupo Parlamentario Catalán en el Senado-Partit Demòcrata Català fue realizada cumpliendo todos los requisitos reglamentarios, dado que ninguno de los diez senadores firmantes formaba parte 
de otro grupo parlamentario, y la denominación final escogida, _ Grupo Parlamentario Catalán en el Senado_-, era conforme «con la que sus miembros concurrieron a las elecciones». Cuestión, ésta última, que habría que matizar, toda vez que, si bien es cierto que no es contrario a lo dispuesto en el artículo 27.4 , no lo es el hecho de que no es la denominación con la que concurrieron todos los miembros del grupo constituido.

Los precedentes en cuanto al «préstamo» de senadores sirven al Alto Tribunal para recordar que en otras legislaturas, —en la VIII con Coalición Canaria y en la IX con el PNV_-, ambos grupos recibieron seis escaños del PSOE, siendo por lo tanto su número originario inferior a seis, lo que, unido a la cesión de cuatro senadores del PP al PNV, le permite afirmar «que descarta que la actual Mesa del Senado haya decidido apartarse de los citados precedentes parlamentarios» (FJ 5).

Reconoce así el TC el amparo a los senadores recurrentes desde la perspectiva de la relevancia autoorganizativa, constitucionalmente reconocida, de los usos parlamentarios, entre los que se encuentra el «préstamo» de senadores. «Préstamo» en el que, en este caso concreto, es «irrelevante la pluralidad de procedencia electoral de los senadores "prestados», la proporción numérica de los que tienen tal condición, o su pertenencia a una o varias formaciones politicas» (FJ 5). Es decir, que para el Tribunal no es relevante ni cuántos senadores ni de qué formaciones políticas proceden los que se «prestan» para constituir el grupo, siempre y cuando no vulneren el Reglamento, obviando la perspectiva del «fraude de ley» en la que se incurre.

Por último, el Tribunal rechaza la presunción de fraude reglamentario efectuada por la Mesa, al considerar que la previsión del artículo 27.2 se ha aplicado «sin baberse dado los presupuestos de becho que lo justificaban y ha impedido la constitución de un grupo parlamentario anticipándose a lo que, a su juicio, entendió que podian hacer los senadores integrantes del mismo». La Mesa, ni podía ni debía adelantar un presupuesto de hecho que no se había producido por partida doble: ni se había constituido el Grupo Catalán ni, por lo tanto, su número se había reducido por debajo de los seis miembros. En suma, se ha aplicado «de forma prematura a un grupo parlamentario non nato, una causa de disolución prevista en el artículo 27.2 RS»(FJ 5).

Concluye el TC que tampoco se tomó en consideración lo declarado por los propios senadores, que reiteraron su compromiso con lo establecido en el artículo 27.2 , esto es, que se mantendría de forma permanente el número mínimo de seis miembros.

En definitiva, reconoce el amparo y declara que sí había derecho a constituir el Grupo Parlamentario Catalán en el Senado, por lo que anula los Acuerdos impugnados por vulneración del artículo 23.2 de la Constitución en conexión con el artículo 23.1. 


\section{CONCLUSIONES}

El llamado «préstamo» de senadores es una práctica parlamentaria que, aun formado parte de los llamados usos y costumbres parlamentarios constituye, sin atisbo de duda, un auténtico fraude de ley, sólo justificado por las sustanciales ventajas políticas y materiales que el reglamento otorga a los grupos constituidos.

La plena constitucionalidad de su uso, —y, sobre todo, abuso—, señalada en la STC 76/2017, de 19 de junio, en nada empece un juicio de racionalidad objetivo en torno a la necesidad de garantizar el cumplimiento del reglamento en su doble vertiente formal y material.

Formal, porque amparados en redacciones confusas, — como la del artículo 23.1 del Reglamento del Congreso- - se forman grupos parlamentarios que no cumplen ni los requisitos ordinarios ni los extraordinarios, —en el caso del Congreso- L La utilización del «préstamo» de diputados y senadores, en este punto, no viene a ser sino una forma de sustraerse a los requisitos cuantitativos exigidos, soslayando los criterios formales.

Y material, porque el sentido de los requisitos para la constitución de grupos parlamentarios contenidos en los reglamentos es doble y, en ningún caso, se cumple: en primer lugar, evitar el excesivo fraccionamiento de la Cámara, —al objeto de mejorar la eficacia de actividad parlamentaria desde la simplificación y el fortalecimiento de la representación de las formaciones políticas que han obtenido escaño-, y, en segundo lugar, favorecer una lógica y adecuada concordancia entre el momento electoral y el momento parlamentario, — evitando disonancias que no hagan fiel el mandato expresado en las elecciones-.

Por ello, quizá sería muy conveniente proceder a una modificación de los reglamentos parlamentarios de ambas Cámaras.

Así, el artículo 23.1 del Reglamento del Congreso de los Diputados debería ser modificado en lo relativo a los requisitos subsidiarios, — cinco diputados y, al menos, el quince por ciento de los votos en las circunscripciones en las que se hubieren presentado, o un cinco por ciento nacional_- por una triple vía: bien reduciendo el número de diputados exigidos; bien evitando que diputados cuyo destino «natural» sea integrarse en el Grupo Mixto puedan adscribirse temporalmente a un grupo parlamentario en formación; o bien, que un diputado proveniente de una candidatura mayoritaria que se asocia a un grupo distinto en el momento de darse de baja no pueda, en toda la legislatura, ser adscrito más que al Grupo Mixto.

La primera de las opciones, relativa a la reducción del número de diputados exigidos, es una alternativa inadecuada, porque si reducimos el nuevo umbral mínimo se acabaría fragmentando en exceso el Congreso, diluyendo la eficacia de la acción parlamentaria y dificultando su adecuada organización.

La segunda vía, por otro lado, tendría la desventaja de que ampliaría el Grupo Mixto, pero fortalecería la representatividad de los grupos y mejoraría la 
organización de la Cámara, evitando la sobrerrepresentación de las formaciones políticas.

La tercera, por último, evitaría el pernicioso espectáculo de los diputados de ida y vuelta de un grupo a su grupo «natural», dado que la mayoría de los diputados, ante la tesitura de verse incluidos contra su voluntad en el Grupo Mixto, evitarían ser utilizados para la formación de otros grupos parlamentarios.

En el caso del Senado, resulta imprescindible también proceder a la modificación del artículo 27.1 de su Reglamento, con una perspectiva prácticamente idéntica a la propuesta para el Congreso: sea reduciendo el umbral mínimo de senadores requeridos para formar grupo parlamentario; sea obstaculizando que senadores destinados al Grupo Mixto formen parte constitutiva de un grupo nuevo para luego recalar en el Mixto; sea, por último, que un senador de las formaciones políticas mayoritarias haga el camino de ida y vuelta a su grupo originario, obligándole a adscribirse, en ese caso, al Mixto.

La primera de las opciones es, quizás, la más correcta en nuestra opinión, fundamentalmente por la propia configuración constitucional del Senado como Cámara de representación territorial, que necesita conjugar el requisito de la organización parlamentaria con la pluralidad territorial, para lo que resulta conveniente favorecer la creación de grupos parlamentarios que reflejen esa diversa territorialidad. En ese aspecto, el umbral mínimo de cinco senadores para constituir grupo propio podría ser un umbral razonable para favorecer el punto de equilibrio entre ambas perspectivas.

$$
\text { *** } *
$$

TITLE: About the constitution of parliamentary groups and the "lending" of members

ABSTRACT: The aim of this work consists in exposing the problems regarding the lending of the members in the Spanish Parliament, analysing the legal framework for the constitution of parliamentary groups within the regulations of the Chamber and the practice followed since the inception of democracy. Subsequently, the jurisprudence of the Constitutional Court will be analysed, specially decisions 64/2002, of 11 March, the 141/2007, of 18 June and the most recent 76/2007, of 19 June. Finally, a proposal for reform of the regulations of the Congress and the Senate is made, in order to limit and avoid this practice.

RESUMEN: El objetivo de este trabajo consiste en exponer la problemática del «préstamo» de parlamentarios en las Cortes Generales, analizando el marco jurídico de la constitución de los grupos parlamentarios en los reglamentos de las Cámaras y la práctica seguida desde los inicios de la democracia. Posteriormente, se analizará la jurisprudencia del Tribunal Constitucional, concretamente, las sentencias 64/2002, de 11 de marzo, la 141/2007, de 18 de junio y, la más reciente 76/2017, de 19 de junio. Por último, se hace una propuesta de reforma de los reglamentos del Congreso y del Senado, al objeto de limitar y evitar esta práctica.

KEY WORDS: lending, parliamentary members, fraud, constitution, parliamentary groups.

PALABRAS Clave: préstamo, parlamentarios, fraude de ley, constitución, grupos parlamentarios.

FECHA DE RECEPCIÓN: 6.03.2018

FECHA DE ACEPTACIÓN: 5.02.2019 
